\title{
Students' Perception of the Methodological Effectiveness of Italian Courses at the Italian Cultural Institute in Osaka
}

\author{
Giuseppe Maugeri (Corresponding author) \\ Dipartimento di Studi Linguistici e Culturali Comparati \\ Ca' Foscari University in Venice, Venice, Italy \\ E-mail: gmaugeri@unive.it \\ Graziano Serragiotto (Note 1) \\ Dipartimento di Studi Linguistici e Culturali Comparati \\ Ca' Foscari University in Venice, Venice, Italy \\ Venice, Italy
}

Received: March 3, 2020

Accepted: March 16, 2020

Published: March 30, 2020

doi:10.5296/ijl.v12i2.16594

URL: https://doi.org/10.5296/ijl.v12i2.16594

\begin{abstract}
By beginning with an analysis of the linguistic policy in Japan, this case study maps the institutions that promote the Italian language and culture in the territory of Kansai, as well as examine the teaching of Italian at the Italian Cultural Institute in Osaka (IIC). The Osaka Institute represents the largest cultural and linguistic centre of Italian in Kansai. Hence, the aim of this investigation is to identify what type of Italian is taught at the IIC, how it is learned, as well as the main reasons that determine the decrease in Italian language students at the centre. By using the holistic Action Research approach, useful data was obtained for the registry analysis of the entities involved in the dissemination of Italian and of the teaching practices carried out in the IIC courses. Furthermore, the data acquired highlights how the prospects of the Italian language in Kansai are closely correlated with the effectiveness of the linguistic promotion of competent institutions, the renewal of the teaching operating models, and the modernization of teaching and evaluation practices.
\end{abstract}

Keywords: Language education, Action research, Holistic approach, Communicate competence, Metalanguage 


\section{The Prospect of Language Teaching in Japan}

In this first paragraph we intend to study the Japanese education system in light of the most recent indications of the Ministry of Education (MEXT). The objective is to connect the perspective of legislative reference, which encourages the teaching and learning of languages according to a communicative logic, with the difficulty of completely defining how language should be methodologically taught and learned. On one hand, there are innovations aimed at internationalizing the language education process, however, on the other, the learning environment in Japan is still conditioned by typical cultural models in the Japanese context. Therefore, the meaning and the social role of the subjects of the learning process respond to the language learned within society. This conditions the teaching methods and tools based on the rigidity of roles (Kariya, 2012), the formalization and the specialization of tasks.

\subsection{Language Policy in Japan (2017-2019)}

In line with Balgoa's studies (2019), the importance of language teaching in Japan is part of the country's internationalization process, which first began by teaching English in primary schools (from 2003) and then with international exchange programs (McRostie, 2017). According to Kubota (2016), this program should encourage new opportunities for growth ahead of the 2020 Olympics in Tokyo. In this regard, a recent law promulgated in Japan (2019) provides that the teaching of the Japanese language is entrusted to the government. This new legislative provision states that foreign residents who intend to study Japanese will be enabled to do so by means of free courses carefully designed according to their needs and interests. Each municipality has the task of identifying resources and putting in place the best strategies for creating language learning opportunities for children, adolescents and adult workers residing in Japan, whose numbers are increasing every year (Fujita - Round \& Maher, 2008). This measure is significant from the philosophical and pragmatic point of view, which, on one hand, pushes Japan to be interested in aspects such as inclusion, multiculturalism, and interculturalism through the teaching of Japanese and, more generally, the teaching of foreign languages. On the other hand, it aims to address the worrying decline in population and number of births in recent years. An interesting interpretation regarding the MEXT linguistic policy is that of Turnbull (2017). He believes that the new ministerial indications on the dissemination of the teaching of Japanese to foreign residents hides the intention to counter the impact of English and other languages, like Chinese, in the Japanese culture and language, since their impact could undermine the Japanese sense of national identity (Lombardi Vallauri, 2018). Hashimoto (2009) alternatively argues that the promotion of the Japanese language serves to spread elements of Japanese culture within the international community. An intermediate position is expressed by Kubota (2016), according to whom English is taught as a SL in Japan because it is recognized as a lingua franca and therefore serves for the economic interests of the nation.

On the didactic side, starting from 2011 the MEXT (Note 2) (an organization pertaining to the Ministry of Education founded in 1977 to merge the Ministry of Education, Science, Sports, Culture and the Science and Technology Agency as a result of the reorganization of central government ministries and agencies) encouraged teachers to give greater emphasis to 
communication in the classroom so that communicative use of the language prevails over the grammatical attitude (Noda \& O'Regan, 2019). Compared to 2015, the latest report of the MEXT (2017) contains the political-pedagogical indications and goals to be able to start a new phase in the curricular programme in which the learning objectives and the ways to achieve them are strictly correlated with the adoption of a communicative approach to teaching languages in public institutions, with the aim of building students' expandable communicative abilities and skills.

This situation is encouraged in the classroom through a series of strategies:

a) new and stimulating teaching materials;

b) contextualization of the language from which to proceed to a better analysis of the linguistic aspect; and

c) the cultural and intercultural deepening of the language being studied so that the student develops critical thinking and judgment of both their L1 and SL.

Hence, there are two considerations. The first is that SL teaching serves to maintain and strengthen L1. The second is the importance assigned to the communicative approach considered a methodological choice aimed at promoting in Japanese learners a greater awareness of the use of the language as a tool of thought and communication within a global community. However, no reference was made to the evaluation system that serves to classify and decide the educational future of young people in Japan (Fujita-Round \& Maher, 2008).

In light of this situation, in order to make the essential educational action outlined by the MEXT possible, it is necessary to hire trained teachers who can realise the teaching actions aimed at achieving these educational and linguistic goals. Following this direction, the MEXT has promoted a system of recognition and accreditation of the skills acquired through obtaining a didactic certification, with different skill levels. According to Pennycook (2017) such a measure aims to reform the quality of language teaching and learning in order to foster the psychological and social growth of students through school and language education courses.

However, in view of the measures adopted by the MEXT, the conditions for teaching and learning languages are in relation to traditional pedagogical-educational references of the context. Mckenzie (2008) believes that the key to methodological renewal is through the training of language teachers so that they have the theoretical and practical tools to build teaching materials and assessment situations in line with the training needs of the learning context.

From this perspective, it becomes useful to reflect on the reality of teaching/learning languages. In this case, the teaching of Italian in Japan, will allow us to underline how the logic of education in Japan highlights different action modes for the student compared to the recent indications of the MEXT. 


\subsection{Language Teaching in Japan}

Unlike English, foreign language teaching in Japan plays a marginal role (Sampson, 2016). According to Horiguchi, Imoto and Poole (2015) this situation is linked to three factors. The first is that the Japanese linguistic policy for the past 25 years has favoured a growing process of 'Englishization' starting with elementary schools in order to prepare future Japanese citizens to face the pressures and new needs deriving from globalization (Kikuchi \& Browne, 2009). Sergeant (2011) highlighted in his studies that the growing symbolic influence of English, which enriches the Japanese vocabulary in artistic fields such as music, is becoming an essential part of scientific and academic terminology. The second factor is related to the absence of a language curriculum and educational goals. In fact, the absence of these operational tools made the usefulness of what they study incomprehensible to students. Accordingly, the research by Kunishige et al. (2011) demonstrates that Japanese university students majoring in English perceive a lack of direction due to the absence of a didactic context in which there are no didactic and pedagogical references. In Ushioda's study (2015), Japanese teenage students say they do not feel adequately motivated by studying English because the school system does not encourage their involvement and full participation in educational activities. In this regard, Al Wassabi (2019) states that the absence of a curriculum risks denying students the opportunity to understand the complexity and richness of the culture of the language being studied. Instead, students come to the memorization of communicative tranche consistent with a type of learning that is relevant only for testing. The studies of Grabe and Stoller (2013) evidently demonstrate the importance of structuring a curriculum which defines the characteristics of language learning. This is a crucial step in promoting five areas of growth in the student: cognitive, affective, emotional, linguistic and metalinguistic.

The third reason is related to the modest methodological preparation of language teachers. Kikuchi and Brown's (2009) research on teaching English to university students in Japan highlighted a traditional view of language and the passive role of learners. The observation of the centrality of the teachers reflects the hierarchical and gerontocratic order of Japanese society (Rose \& McKinley, 2018). Another aspect observed was the teaching focused on grammar, where translation activities are considered as the privileged way to give students proof of having correctly understood and applied the morphosyntactic rule. The analysis outlined would be in line with the traditional strategy of organization and construction of content to which Japanese students are accustomed; by beginning with learners' own L1, the foreign language sentence is translated word by word following the reading technique defined by yakudoku (Mamiko \& O’Regan, 2019).

This explains how the meaning of the foreign phrase passes through the Japanese translation of the phrase, generating effort and slowing down the pace of acquisition (Hino, 1988).

A similar teaching context reveals a wide range of elements and didactic choices that strongly disagree with the pedagogical indications of the MEXT (2003). Therefore, the language teaching training of teachers becomes a priority political act. Gottlieb (2008) argue that updating language teaching is a relevant educational issue that should be addressed by not only defining its goals but also its course that can be used to translate these goals into reality. 


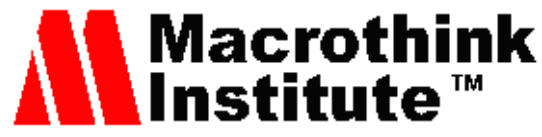

International Journal of Linguistics

ISSN 1948-5425

2020, Vol. 12, No. 2

This is for teachers to be consciously prepared from a language teaching point of view, to be aware of their didactic choices, and to have the theoretical-practical tools to solve students' linguistic problems. Therefore, in order to produce a change in the language education system in Japan, it would be advisable to devote more emphasis on how the training and glottodidactic updating interventions should be developed and organized so there can always be a clear scientific focus and an operation that gives meaning and shape to the training needs of language teachers involved. The constant and coherent articulation between the theoretical project and the implementation of these training courses should define a constant training over time which can be accessible through the use of NT. In addition, these courses should be attentive to different dimensions of teaching related to the neuro-psychological sphere of the student or to the teaching techniques of authentic materials. Greater efficiency in language teaching could decrease students' sense of demotivation and frustration caused by the inability to understand in the classroom.

\subsection{The Teaching of Italian in Japan}

Although today's economic conditions are profoundly different from the economic bubble of the 1980s, the Italian language still attracts interest in Japan today (Thompson \& Yanagita, 2017). The fascination for cultural events in the Bel Paese and for products 'made in Italy' retains its authority in large cities. Opera, art, design, cuisine and literature are some of the Italian areas that generate curiosity and attract the Japanese. Therefore, Italian is recognized as a language of culture. Considering this phenomenon, the need to build a linguistic offer that can meet multiple requests has prompted a large variety of language institutes to open Italian courses.

In Tokyo, for example, there are a multitude of associations (for example, the Italian Japanese association; or the Italian Japanese institute founded in 1970) that are engaged in a long tradition of promoting the Italian language. Over the years, cultural centres, schools (for example, Berlitz) and private institutions have seen an increase in the number of locations in the city, which demonstrates the increase in language courses in the area.

One aspect to note is that this gradual growth of Italian courses at language institutes in Japan is often of a quantitative and non-qualitative nature. The selection of the teaching staff aims to employ either Italian native-speaking students who were in Japan for study reasons, often in a field other than language teaching, or native-speaking teachers who are selected without a specific professional profile suitable for teaching. Accessing the Italian language in these conditions portrays a teaching practice that does not respect the specificity of the student. The teachers being selected do not have the theoretical knowledge or the skills to design and develop courses that can personalize learning. The spread of such a phenomenon could explain the decline in the last ten years of Italian as a language of study in private centres. This is because each centre performs a self-referential function and places itself in a condition of competition and isolation from the territory.

In many private realities observed, the teachers lack an educational coordination and an organization that underlies the specific educational, glottodidactic and pedagogical choices of 
the courses. Thus, each of their linguistic events is disconnected from the network of their colleagues' lessons.

The absence of an educational committee has further effects on the teaching of Italian. Teachers lack spaces to communicate, share, and discuss collective evaluations of courses, all of which are necessary to redirect and improve current offers for training.

A second reflection regarding the training tools used for teaching Italian is that these institutions rarely invest in improving environmental and technological conditions. As a result, there is no linguistic and cultural growth project for the students that builds their experience or considers multiple important aspects of learning. These being the reflections of each individual student and their class group, the quality of interpersonal relationships built in class as well as the personal meanings perceived through the discussion of sociolinguistic and sociocultural aspects with the teacher.

All in all, there are no conditions for evaluating observable and measurable actions, nor is it possible to analyse their real contribution in improving the quality of teaching and learning Italian in the territorial context in which they operate.

A second category of centres specialized in teaching Italian to foreigners are represented by the Italian Cultural Institute (IIC.) The Italian institutes are cultural offices of the Embassy of Italy that have different responsibilities from private language schools. Therefore, these bodies pay great attention to the quality of the cultural and linguistic product they provide in addition to the management and enhancement of the student, who is considered a customer. Such a multifaceted vision provides an identity aspect that unfolds in a careful management analysis of financial and human resources, insisting on the professionalism of the teaching staff. Subsequently, actions towards the promotion and organizational strategy for teaching Italian in Japan by the IICs of Tokyo and Osaka were deemed necessary. Such an orientation towards teaching Italian translates into:

a) recruiting native speaking teachers who are trained and in possession of a didactic certification for teaching Italian to foreigners; and

b) guarantying their support to update teaching language through scholarships for teachers and training meetings conducted respectively by specialized Italian universities.

Overseeing the didactic quality of the courses thanks to a Didactic Committee which includes teachers, student representatives and the IIC cultural officer.

With existing contexts of cultural and linguistic experiences related to Italian, today more than ever the presence of two Italian governmental cultural institutes based in Tokyo and Osaka guarantee a continuous presence and a reference point for the diffusion of Italian in Japan.

To summarize, the position of the IICs in the language market concerning Italian seems different from the organizational method of teaching Italian provided in private schools. The differentiation concerns the type of mission and vision that each body has and the specificity of roles and responsibilities. The latter, involves different remuneration levels in order to 
build a language learning system connected to an external cultural marketing perspective and an internal perspective; each contributes in a growth plan for the qualitative functioning of teaching.

The third category of centres where Italian is taught are universities. The latest field research (Diadori et al., 2017) has revealed that there are about 80 universities, including public, state and private that offer Italian language courses in Japan. According to the information communicated by the Embassy of Italy in Tokyo (2019), these universities are specialized in linguistic or humanistic studies in addition to universities that offer the possibility of coordinating scientific study plans with linguistic insights.

An initial analysis of the organization of the Italian curriculum at these institutions allows us to identify some common design and methodological elements that prove to be in line with both the Confucian Pedagogical Framework of Reference in Japan and a methodology centred on the uncritical knowledge of learning declarative, grammatical and morphosyntactic contents (Zamborlin, 2003). In a teaching environment like this, the teacher presents in class for a long time which develops in the individual a perspective of mnemonic learning. This leaves no room for forms of linguistic, metalinguistic and cooperative reflection.

\subsection{The Teaching of Italian in Kansai}

The territorial context taken into consideration is characterized over time by the sudden development and closure of Italian courses in institutions of different profiles. This liquid dimension is important to keep track of, consolidate relationships in, and interact with in order to insert all these realities engaged in the promotion of the Italian language and culture into a development program that aims to give specific relevance, purpose and continuity to the teaching of Italian.

This premise is useful for understanding how the teaching of Italian in Kansai took place in a fragmented, non-continuous, non-coordinated way. Hence, the Osaka IIC directed by Dr. Stefano Fossati had to, above all, be aware of the multiformity of the realities engaged in the diffusion of Italian in the context of competence. In this regard, the IIC considered that a key action for the type of management of the Italian language was to map, guide and monitor all the bodies active in Kansai towards a clear and common idea of what it means to teach Italian in Japan and towards building critical, reflective and workable communication skills. The interest in this design and management approach has suggested integrating a holistic strategy that would identify the diverse entities competent in the promotion of the Italian language and culture in the territory. Moreover, the strategy would implement a common linguistic policy characterized by strong synergy and effective planning. By reflecting on the various themes of Italian teaching, it has been found that numerous interlocutors have committed themselves as a critical resource for understanding the effective value of a shared strategy and vision. For examples, the activated twinning programmes between Italian and Japanese universities through the initiative and intermediation of the IIC in Osaka. 
With this perspective in mind, the 'Italian language Observatory' project was launched. The entities that had joined the project deemed it useful to find visibility within a category of subjects that can be enhanced through a formal system and a series of common initiatives that come with undoubted benefits in terms of operational tools and lower costs (for example, the circuiting of exhibitions and works).

This prospect of investigation has made it possible to identify these bodies and contextualise their activities in the field of teaching the Italian language and culture.

Within the population of Western Japan, which is equal to 61,124 , the Japanese who study Italian are divided as follows:

Table 1. Italian students in Western Japan. Academic year 2017-2018

\begin{tabular}{ccc}
\hline Institutions & Number of students & \% \\
\hline University & 24.950 & 59.51 \\
\hline IIC & 8302 & 19.80 \\
\hline Dante Alighhieri Society & 1035 & 2.47 \\
\hline Other Schools & 7641 & 18.2 \\
\hline Tot & 41.928 & \\
\hline
\end{tabular}

Analysing the data, most students study Italian in universities. As of 2017-2018, Italian is studied 36 Kansai universities, divided as follows.

Table 2. Universities where Italian courses are active. Academic year 2017-2018

\begin{tabular}{ccc}
\hline University & Quantity & \% \\
\hline State Universities & 5 & 13.89 \\
\hline Public Universities & 3 & 8.33 \\
\hline Private Universities & 28 & 77.78 \\
\hline
\end{tabular}

The geographical distribution of universities in Kansai which hosts the largest number of students can be organized according to the territorial areas in which they operate.

Table 3. Territorial distribution of universities where Italian is studied. Academic year 2017-2018

\begin{tabular}{ccccccc}
\hline Prefecture & $\begin{array}{c}\text { State } \\
\text { Universities }\end{array}$ & $\begin{array}{c}\text { \% on } \\
\mathbf{5}\end{array}$ & $\begin{array}{c}\text { Public } \\
\text { Universities }\end{array}$ & $\mathbf{\% 3}$ & $\begin{array}{c}\text { Private } \\
\text { Universities }\end{array}$ & $\begin{array}{c}\text { \% on } \\
\mathbf{2 8}\end{array}$ \\
\hline Aichi & 1 & 20 & 1 & 33.33 & 9 & 32.14 \\
\hline Hyogo & 1 & 20 & 1 & 33.33 & 5 & 17.68 \\
\hline Kyoto & 2 & 40 & 1 & 33.33 & 7 & 25 \\
\hline Nara & 0 & 0 & 0 & 0 & 1 & 3.57 \\
\hline Osaka & 1 & 20 & 0 & 0 & 7 & 25 \\
\hline
\end{tabular}

According to Table 1, the second reality in which Italian is studied is with the Osaka IIC. Among the cultural events and manifestations of the Italian language, the activities of the IIC 


\section{Macrothink}

International Journal of Linguistics

ISSN 1948-5425 2020, Vol. 12, No. 2

stands out in Osaka because their training proposals represent an opportunity for those who want to learn Italian continuously.

Unsurprisingly, the cultural initiatives of the IIC in Osaka were concentrated not only in the city itself, but also in other cities belonging to its jurisdiction and in areas that, until then, had only been marginally affected by its work or even not at all (Figure 1).

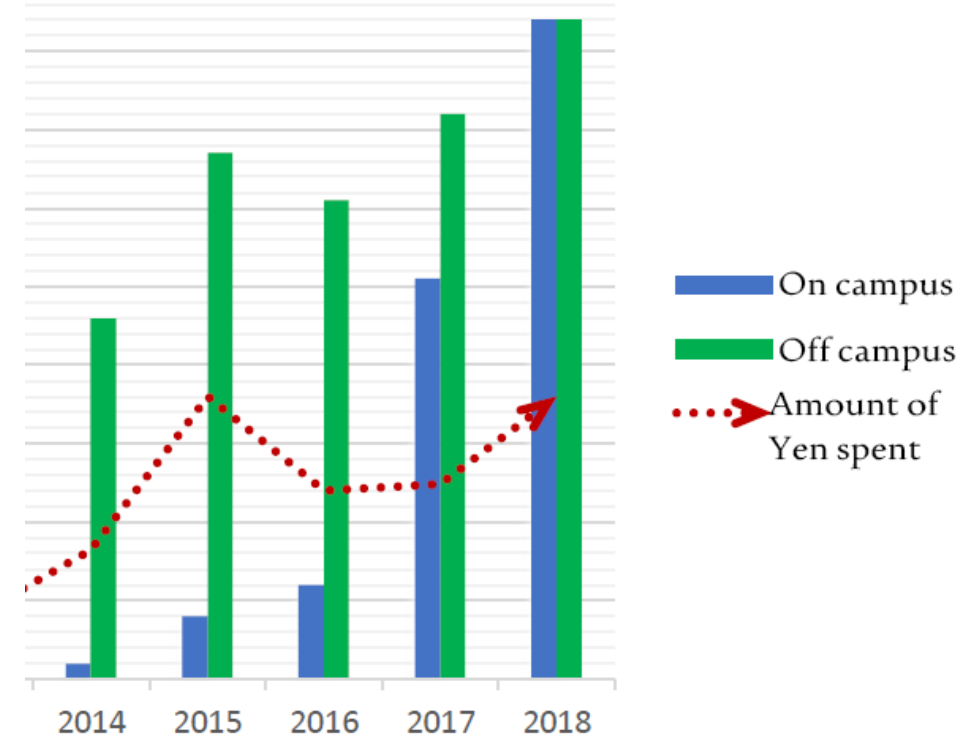

Figure 1. Analysis of off-site events of the IIC

Source: processed by the Osaka IIC

Based on these assumptions, the research project promoted by the Osaka IIC has set itself the objective of offering an organic vision of their actions practiced in favour of learning Italian. In this way, qualitative feedback can be given to the IIC management regarding their need to better understand the didactic phenomenon and to consider problems in the linguistic paths that led to a non-increase in enrolments and a decrease in the motivation to learn Italian.

\section{The Research-Action Project}

The demand to map the entities involved in the diffusion of Italian language and culture in Kansai, together with a greater attention to the quality of teaching Italian at the IIC in Osaka, prompted the IIC to create an Italian language Observatory in Kansai. In collaboration with the ITALS Lab of the Ca 'Foscari University of Venice, the Observatory has set itself the objective of collecting qualitative and quantitative data regarding the didactic reality of the IIC. This will enable the IIC to take note of the didactic problems in the courses and develop a training project for the Italian teachers that assists them in carrying out the most suitable educational and training courses to help learners understand Italian culture with all its distinctive skills. 


\section{Al Macrothink}

International Journal of Linguistics

ISSN 1948-5425

2020, Vol. 12, No. 2

In this research, the contribution of the teachers and students attending the IIC courses has been decisive in identifying specific needs of Italian teachers and putting them in training courses that can improve the quality of Italian learning and teaching processes.

\subsection{Research Questions}

Since the research is aimed at constructing an information set is for a specific area that has few case studies, it starts from a place of clear, significant and goal-oriented questions (Nassaij, 2019).

The questions that guide the realization of the research are:

a) how is the Italian language taught and learned at the IIC?

b) what kind of Italian is taught by teachers?

c) why has there not been an increase in students in recent years despite the attention that the IIC has given to teaching Italian?

The research questions are relevant and appropriate to the development of the survey because they aim to create a dimension for the context and highlight the obvious reasons (teaching, learning quality, environmental conditions, students' motivations) that justify a poor growth of Italian students. These questions aim to determine whether there is a connection between the methodological choices of the Italian teachers and the students' learning style and system of needs and motivations. If the teachers' strategy has a binding relationship with the cultural norms of the context or responds to a precise logic of acquisition of lexical and morphosyntactic contents that enable students:

a) to be independent in choosing content of specific interest and in accessing to the Italian cultural dimension; and

b) to increase the level of stimulation and linguistic-communicative knowledge of Italian by strengthening critical, cognitive and evaluative skills related to the quality of the Italian study experience.

Then, the formulation of the questions is closely related to the objectives of the investigation. Therefore, they will play a strategic role in addressing the observation in the field by clearly defining the data that needs to be obtained.

\subsection{The Research Methodology}

Considering the type of project and its objectives, the Action Research approach was adopted for the investigation.

Burns (2011) emphasizes that Action Research approach aims to solve the problem in a way that provides an entirely new action framework with practical solutions for teaching in a specific context. Hence, the exploratory intervention has been defined and constructed in relation to the context and objectives identified (Dörnyei, 2014).

In line with Creswell's (2003) studies, the adoption of this case study approach seeks to: 
a) start a reflection on the context and analyse the opinions and perceptions that the students have regarding their learning experience and their training needs.

b) develop a work plan aimed at giving concrete solutions (Blake, 2007); and

c) offer language teachers a useful research model for the development of reflective practices (Karnieli, 1998) so that they can re-examine their role and develop didactic practices aimed at satisfying the needs of the students.

As Denzin and Lincoln (2000) argue, the teachers themselves are an active and critical part of the Action Research. According to the studies of Kemmis et al. (2014) teachers can derive a series of advantages by participating in the Action Research and subsequent reflection. Namely, a better understanding of the context in which they operate, a design framework which can be used for the development of a curriculum that directs students to test effective linguistic-cognitive strategies and understand the linguistic and cultural reality studied (Nugent, 2019), and finally a greater awareness of management and collaborative work practices aimed at enhancing the potential of students (Convery \&Townsend, 2018).

According to Dörnyei (2014), the holistic nature of research takes shape from a single exploratory perspective and practice which, starting from the survey questions, takes into consideration a combination of various factors such as the emotional and cognitive aspect of the informant. The manifestation of these two components represents the built idea the student has regarding the learning experience, which guides their behaviour and evaluation (Glenn, 2011). Hence, these two components should be considered in the light of the entire case study. On a methodological level, the holistic research approach considers aspects that belong to qualitative and quantitative approach (Bolagari \& Hajimaghsoodi, 2017).

\subsection{The Objectives of the Research}

The objective of the research is not to investigate how much Italian is taught. On the contrary, the research investigates the methodological and didactic practices carried out in the classroom in order to understand what kind of language is taught and how the language is presented. Therefore, interest has shifted to the qualitative aspect of the teaching process in order to recognise which teaching tools and techniques are favoured by the teacher during the lesson and to inquire the opinion of the informative sample regarding the didactic reality that was offered to them. In other words, the research objectives are:

a) identifying current teaching methodologies and verifying their consistency and effectiveness with the teaching goals and needs of Italian students;

b) establishing whether the current teaching approach is in line with the strategic indications of the MEXT that we have previously mentioned, where communication is a distinctive feature of the learning context and the language is practiced at the level oral and written production; and

c) understanding if the effective capacity of these approaches to teaching Italian responds to a specific curricular plan that is heading in the direction of applicative cases, or in the direction of a practical use of the language with connection to the real world. 


\section{Macrothink}

Therefore, the present case study aims to detect what happens in the classroom in order to reach a balanced perspective regarding the teaching quality within the IIC Italian courses. A proposal is then formulated based on the problems identified. The proposal aims to solves these problems of linguistic competence on the students' part and of glottodidactics on the Italian teachers' part.

\subsection{Research Tools}

Through the research, the methodological problem focused on restoring the overview of the didactic reality in the IIC courses. Therefore, the following a set of tools were available:

a) field observation;

b) logbook;

c) workflow of the interactions;

d) interviews;

e) focus group; and

f) questionnaires.

The functional tools for the methodology field research have been able to detect the phenomenon within a not particularly large territorial field. The disadvantages and rigidities that the use of a questionnaire and interview pose were resolved by integrating an open and freer comment section into the questionnaire and asking questions relevant to the didactic reality in interviews and focus groups. The raised questions stimulated the informative sample group to either deepen the observed aspect or qualify the informants' self-observation out loud, generating a less asymmetrical situation between the interviewer and the interviewee (Balboni, 2007).

\subsection{The Sample Group}

The support of the IIC staff was indispensable in analysing the didactic and organizational reality of the IIC in Osaka and in obtaining significant variables for research. Particularly, highlighting students' emotions, opinions and problems related to the Italian teaching environment. The construction of this sample group is closely related to their operations at the IIC, being first contact persons involved in the teaching of Italian. Therefore, the availability of this sample group was relevant and decisive in reaching a complete perspective on the aspects investigated by the research.

\section{Research}

In this chapter the research data will be presented. The organization of this summary will be based on the questionnaire sections and on the interviews which, together with the data collected from the observation grid in the classroom, were found to be more significant in qualitatively describing the reality of teaching and learning Italian at the IIC in Osaka. 


\subsection{The Action Research Framework}

As anticipated, we wanted to have a typological variety of data from several sides in order to obtain and interpret feedback related to the internal factors of the informants.

Based on these assumptions, the research was carried out in the 2017-2018 academic year, according to the ordering parties' requests (Osaka IIC):

Table 4. Research work plan. Academic year 2017-2018

\begin{tabular}{|c|c|c|}
\hline Research period & \multicolumn{2}{|l|}{ 2017-2018 } \\
\hline Ordering parties & \multicolumn{2}{|l|}{ IIC Osaka and MAECI } \\
\hline External agent & \multicolumn{2}{|l|}{ ITALS Laboratory } \\
\hline Sample group & \multicolumn{2}{|c|}{$\begin{array}{l}\text { Native Italian teachers from the IIC } \\
\text { Japanese IIC students }\end{array}$} \\
\hline Focus and content & \multicolumn{2}{|c|}{ Understand the didactic situation } \\
\hline Purpose & \multicolumn{2}{|c|}{ Develop critical awareness in teachers } \\
\hline Methodology & \multicolumn{2}{|c|}{ Holistic } \\
\hline \multirow[t]{2}{*}{ Research tools } & Quantitative & Qualitative \\
\hline & $\begin{array}{l}\text { Observation } \\
\text { Observation check list }\end{array}$ & $\begin{array}{l}\text { Logbook } \\
\text { Interviews } \\
\text { Questionnaires } \\
\text { Focus group } \\
\end{array}$ \\
\hline Data collection method & \multicolumn{2}{|l|}{$\begin{array}{l}\text { On campus } \\
\text { Online }\end{array}$} \\
\hline $\begin{array}{l}\text { Results and possible } \\
\text { application }\end{array}$ & \multicolumn{2}{|c|}{$\begin{array}{l}\text { Interpretation, evaluation and dissemination of results using } \\
\text { an experimentation model to update teachers in a blended } \\
\text { mode. } \\
\text { Organization of seminars and publications. }\end{array}$} \\
\hline
\end{tabular}

In the economy of the present investigation, the work plan developed over a medium term period in order to allow the external agent to collect information and data, in person and online, in a multifaceted reality, where a differentiation was thought to exist between the didactic activities of classes and the various linguistic courses. Another aspect relevant to the timing of the research is the variation of learner categories depending on the lessons' time slot. This was interpreted as a possible factor affecting the teachers' methodological choices in experimenting with different working methods depending on whether the learners were children, adolescents or adults. Moreover, the different typology and distribution of the courses during the semester constituted as a useful element to continue monitoring the learning status and the perception of font people compared to what happens in the classroom.

\subsection{Analysis of the Institutional and Educational Environment}

Useful tools were used to analyse the institutional context in order to understand the function of the organization. Hence, reaching a conclusion that clearly demonstrates the physical and 
didactic project-based characteristics of the IIC. This will allow suggesting a redesign for the organizational structure and planning the process of teaching Italian at the institute.

\subsubsection{The Headquarters and Institutional Environments}

The development phase encouraged by the National Management System includes the institutional environment as the background of an authentic Italian scenario. Therefore, the location must represent a new Italian geometry that proves effective in attracting two heterogeneous (but not excludable) aspects, namely the historical-artistic link with the territory and the people.

Defined in terms of image and result, the location that hosts the institute is not adequate to support Italy's prestigious role in Osaka. The economy and the general quality of the environments are not designed to suit the objectives pursued at a strategic level by the MAECI. Therefore, it becomes difficult to evaluate the applicability of these contexts to cultural and didactic practice.

In 2013, the institutional headquarters moved from Kyoto, one of the cultural centres of Japan, to Osaka.

The headquarters is one of the most important neighbourhoods in the city from an economic point of view. The building that houses the IIC enjoys aesthetic recognition for vertical and cultural development; it is home to a well-known theatre and other organizations that update their cultural program according to the stylistic changes taking place.

The IIC offices enjoy a broad view of the city that does not actually contribute to the success of the organization. The environmental project was designed for a non-cultural office, so using the 200 square meters of available space to host cultural or linguistic events is highly unlikely. In this way, the realisation of the spatial reality with just four classrooms is neither strategic nor proportionate to the communicative objectives of the Italian courses. The classrooms are fixed, small and separated from each other using plasterboard. Aware of the spatial limits, the management has undertaken a series of structural and aesthetic interventions in order to make learning activities sustainable. For example, the aesthetics of the classrooms have been renewed and new technologies have been included along with a minimum heating/cooling system to make the classroom experience more comfortable. Despite these improvements, the classrooms for all age groups remain monotonous; with a white screen, no windows or natural light. Instead, there is only low lighting which strains eyesight. In addition, the classroom space prevents movement and does not facilitate the flow of interaction between students. The communication project is therefore not very effective and for this reason the director asked MAECI for funds in order to proceed with a change of location. Due to the updating strategies of the National Management System and the high number of people who interact every day with the environments of the IIC, a change in location would facilitate the creation of communication, a new image and more organized cultural and linguistic experiences, with a greater value related to the needs of users. Despite efforts to improve environmental conditions, management still finds itself with the same 
spaces that limit its image, its distribution of courses and relationships between people and work practices.

In this regard, the observation sheet of the students' interactions with the IIC's learning environments confirmed that their distribution during the courses held in these spaces reduces their methods of interaction and contact with the secretarial desk. This is where announcements are usually made for events and courses, where main communications occur as well as payment for courses.

Table no. 5 illustrates the distribution of interactions outside the classroom recorded over three weeks of observing the students on campus. The registration took place through collaborating with several people located in the spaces listed below in the observation grid.

N. of students: 64 Total n. interactions: 73

Table 5. Interaction workflow. Personal elaboration

\begin{tabular}{|c|c|c|c|c|c|c|c|c|c|}
\hline \multirow{4}{*}{$\begin{array}{l}\text { Places } \\
\text { interaction }\end{array}$} & \multirow{4}{*}{$\begin{array}{l}\text { N. of } \\
\text { interactions }\end{array}$} & \multirow[t]{4}{*}{$\%$} & \multicolumn{7}{|c|}{ Types of interactions } \\
\hline & & & \multirow{2}{*}{\multicolumn{3}{|c|}{$\begin{array}{l}\text { Duration of } \\
\text { interaction in } \\
\text { minutes }\end{array}$}} & \multicolumn{2}{|c|}{ Formal } & \multicolumn{2}{|c|}{ Informal } \\
\hline & & & & & & \multirow[t]{2}{*}{$\mathrm{n}}$. & \multirow[t]{2}{*}{$\%$} & \multirow[t]{2}{*}{ n. } & \multirow[t]{2}{*}{$\%$} \\
\hline & & & & 5 & $<5$ & & & & \\
\hline Lobby & 24 & 32.8 & 7 & 17 & & 19 & 79.1 & 5 & 20.1 \\
\hline Secretarial desk & 39 & 53.4 & 15 & 19 & 5 & 39 & 100 & & \\
\hline $\begin{array}{ll}\text { Outside the } \\
\text { Classroom }\end{array}$ & 6 & 8.2 & & & 6 & 4 & 66.6 & 2 & 33.3 \\
\hline Library & 2 & 2.7 & & & 2 & 2 & 100 & & \\
\hline Teachers' Office & 2 & 2.7 & & 1 & 1 & 2 & 100 & & \\
\hline $\begin{array}{l}\text { Management } \\
\text { Office }\end{array}$ & 0 & & & & & & & & \\
\hline
\end{tabular}

The analysis of the interaction workflow underlines the points of contact between participants within the IIC space. Most of the interactions take place at the secretarial desk which was considered by management to be a trigger for fast and effective communication with users. It is no coincidence that the secretarial desk had been placed in an area with great exposure and space. This allows the desk to act as a reference point for each hub and as a strong point of contact with the public.

\subsubsection{The Didactic Organization of Italian Language Courses at the IIC}

The strategic orientation of the educational organization of the IIC has successfully attracted part of the market: students who have expressed interest in the Italian language and culture. This has determined a position for the cultural product which the linguistic services offer, attracting the attention of a clientele mainly over 50 and of wealthy social class, in comparison to the higher costs of private schools. This is due to the prestige of the IIC in the territory and the quality of didactic and complementary services the courses provide. 
Such a market angle has had an impact on an organizational level. The distribution of courses as semesters in which the general language courses that have a high frequency of students are distributed in non-binding slots (in the evening), and each is repeated once or twice a week. Hence, requiring a commitment that is not too demanding for the mostly retired customers.

Another aspect relevant to the didactic organization is the didactic committee strongly desired by the management team. This includes coordinating a group of IIC teachers who, in practice, have never produced models and tools for verifying courses. The aim is to offer the IIC teachers an ongoing model of training courses through which each teacher can put together resources and material. This is also useful to overcome the sense of isolation which each teacher can find themselves in. Moreover, the model will help share common practices for the supervision and reflection on the quality and impact of the courses.

\subsection{Conformation of the Research Sample}

The sample group consists of the IIC teachers and students. The first category was reached through a mailing list in order to coordinate availability and interest to participate in the questionnaire, the focus group and the interviews. The students, on the other hand, were informed a week before the researchers arrived. Such scheduling facilitated the compilation and return of the questionnaires both in person and online which, as previously mentioned, continued until December 2018.

144 students and 16 Italian teachers participated in the research. Most of them returned the questionnaire in person (87\%), while a group of students $(23 \%)$ returned the survey via e-mail in the period between December 2017 and December 2018. Another observation to add is that the students limited themselves to answering the structural questions and left the open questions unanswered, while the Italian teachers provided additional comments and clarifications, fully describing the current glottodidactic framework.

Table 6 provides a systematic analysis of the gender of participants in the two categories of informants who collaborated in the research.

Table 6. Characteristics of informants involved in the research. Personal elaboration

\begin{tabular}{|c|c|c|c|c|c|c|c|}
\hline \multicolumn{8}{|c|}{ Research Informants } \\
\hline \multicolumn{4}{|c|}{16 Teachers } & \multicolumn{4}{|c|}{144 Students } \\
\hline M & $\%$ & $\mathrm{~F}$ & $\%$ & M & $\%$ & $\mathrm{~F}$ & $\%$ \\
\hline 9 & 56,2 & 7 & 43,8 & 32 & 22,2 & 112 & 77,8 \\
\hline
\end{tabular}

While the male gender prevails in the category of teachers, the female gender prevails in the student data. Figure 2 proposes a clarification in relation to the age groups of the two categories of informants. 


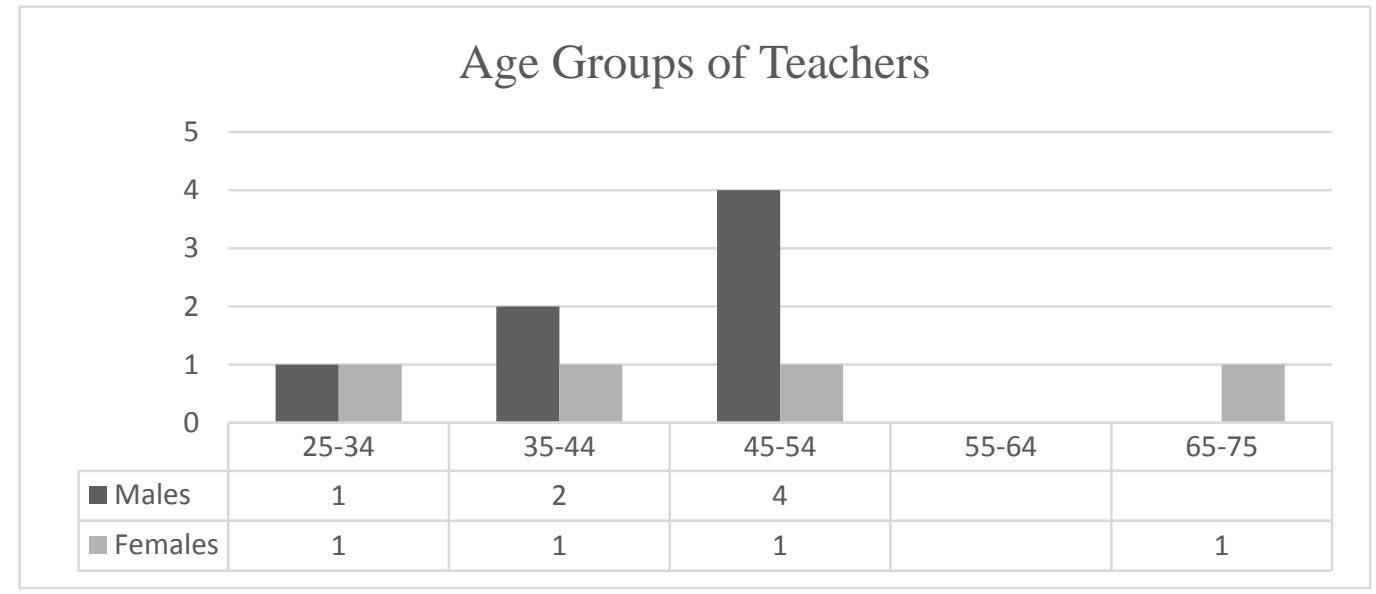

Figure 2. Personal characteristics of the teachers. Personal elaboration

Figure 2 shows a breakdown of the registry of teachers who are mainly in the intermediate age group for both genders and who say they have more than 5 years of Italian teaching experience in Japan.

The analysis of the age group of students becomes crucial to assess the characteristics and structure of Italian classes, which the teachers will use as a basis to choose an adequate teaching methodology. In this regard, Figure 3 informs us that out of 144 participants, 23 informants did not declare an age, 9 of which are male students (28\%) and 14 females (60\%).

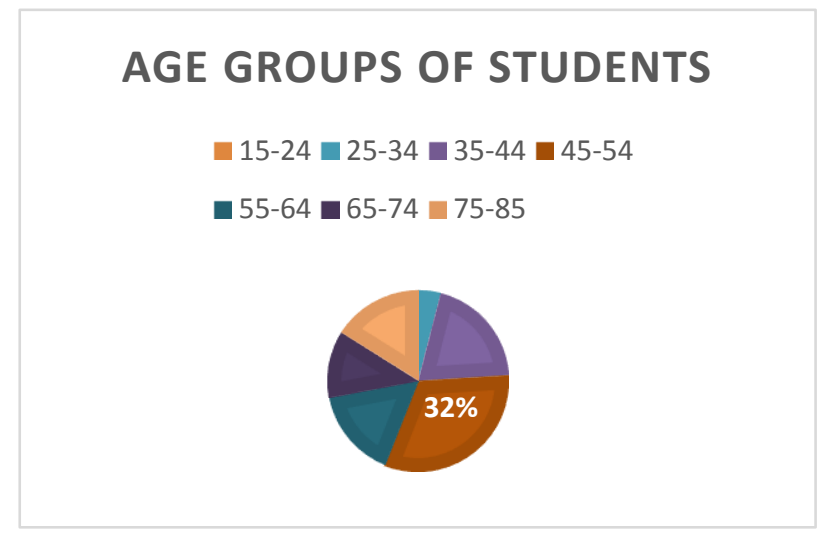

Figure 3. Age groups of IIC students in Osaka. Personal elaboration

The aspect that emerges from the observation of the age distribution of the students is that the seniority group prevails with $32 \%$ of the students in the middle age group, $16 \%$ between 55 to 64 and only a few students of younger ages. Such a varied class structure could create difficulties in the methodological choice of teachers. Hence, from an anagraphic, sociolinguistic and sociocultural point of view, there is a need to adopt an approach that favours differentiation in such heterogeneous classes. This can be done by setting activities on multiple levels in order to enhance logical processes and strengthen different language skills.

The didactic training of Italian at the IIC involves different language levels. Figure no. 4 describes the level at which students declare they are. 


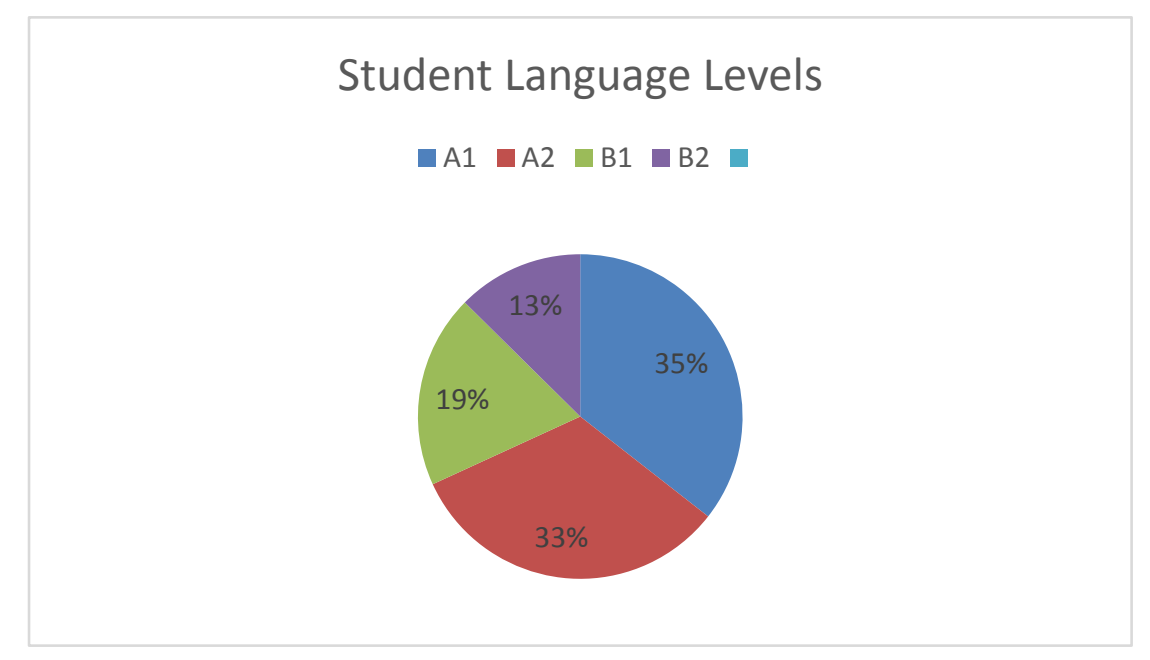

Figure 4 Language level of IIC students. Personal elaboration.

A first evaluation of the data in Figure no. 4 highlights how primary Italian language courses are predominant, while intermediate levels represent the arrival point of the student's progress and advanced levels are completely absent. Therefore, the direction to follow in this context would be to design advanced linguistic paths to guarantee development and greater depth to the learner's language training.

With this analysis in mind, further considerations must be taken into account regarding the duration of each linguistic level. This is in order to acquire in-depth knowledge of the programming of Italian courses. As mentioned, each course takes place over one three-month period. There are one or two lessons weekly, depending on the type of request that is made ex ante, for which the class will conclude the course for a particular level after 8-9 months of lessons. Not surprisingly, A1 students declare that they have been studying Italian for $8 / 9$ months, more than enough time to amalgamate the group of students and retain their loyalty around the teacher figure. Two implications ensue: the first is cultural in nature, so students will continue their study with the same initial reference figure, taken as a model and as a guide for the discovery of such a typologically different language. The second implication is that the students will rely solely on the teacher for initial training, without critical reciprocity to refine their observation strategies of the shared language. Therefore, students will not be able to deal with the different Italian sociotypes of each teacher, but they will be faithful in the teacher's ability to transmit linguistic knowledge by virtue of his or her authority and credibility as a native speaker.

Another factor that represents a useful element for building the informants' profiles is related to previous linguistic experiences (Table 7). 


\section{Macrothink}

Table 7. Foreign language knowledge of IIC students. Personal elaboration.

\begin{tabular}{|c|c|c|c|c|c|c|c|c|c|c|c|}
\hline \multicolumn{11}{|c|}{ Language skills of IIC students } & \multirow{2}{*}{$\begin{array}{l}\text { Tot. responses: } \\
102\end{array}$} \\
\hline & A2 & & B1 & & B2 & & C1 & & $\mathrm{C2}$ & & \\
\hline & n. & $\%$ & n. & $\%$ & n. & $\%$ & n. & $\%$ & n. & $\%$ & \\
\hline English & 1 & 0.9 & 38 & 37.2 & $\begin{array}{l}1 \\
3\end{array}$ & 12.7 & 8 & 7.8 & 9 & 8.8 & $67.6 \%$ \\
\hline Chinese & 1 & 0.9 & 14 & 13.7 & 4 & 3.9 & & & 2 & 1.9 & $20.5 \%$ \\
\hline French & & & 5 & 4.9 & & & 2 & 1.9 & & & $6.8 \%$ \\
\hline German & & & 5 & 4.9 & & & & & & & $4.9 \%$ \\
\hline
\end{tabular}

The analysis of Table 7 takes into account the linguistic level declared by 102 students out of $144(70.8 \%)$ compared to other foreign languages. Most students report having an intermediate level of linguistic knowledge in English and in Chinese (with a lower percentage for Chinese). On the other hand, the percentage of those who report an advanced level is very low in both English and Chinese. This phenomenon may correspond with the absence of linguistic proposals for Italian in IIC courses. The hypothesis is that the intermediate level of a language may have a weight and a level of attribution of social sense that pushes the students to reach a sufficient level of personal and interpersonal linguistic efficacy.

A final element to underline is that the self-assessment of the students' linguistic level has not been certified through the acquisition of linguistic certifications, so the data is filtered and selected by the student, perhaps not always consciously, with respect to previous or current language courses. From these group of students, however, there are subjective variables corresponding to six of them $(5.2 \%)$ who have made it clear that they have obtained a linguistic certification for the levels they have reported.

\section{Analysis of the Student's Perception of the Linguistic Experience}

In the first section of the questionnaire (Figure no. 5), questions were asked to detect the quality of the learners' linguistic experience. The most relevant data obtained from this first block of questions highlight the motivations that led students to undertake Italian language studies and the process of assessing their own well-being with respect to what happens in the classroom. 
1. Why do you study Italian? (Indicate only one option).

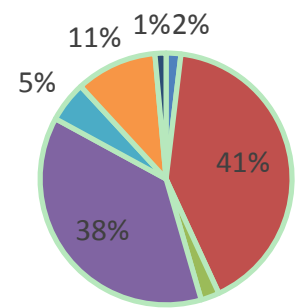

$2 \%$

$\begin{array}{ll}\square \text { to study at university } & \square \text { because I like Italian language and culture } \\ \square \text { to work in Italy } & \square \text { to travel to Italy } \\ \square \text { to read Italian books } & \square \text { to watch Italian films }\end{array}$

- to befriend Italian people

2. During the lesson I feel: (indicate a maximum of two options).

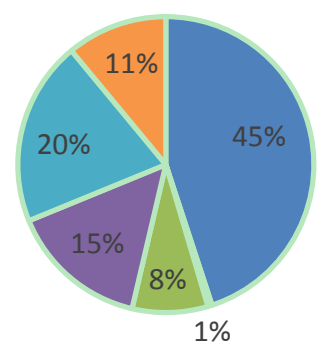

notivated $\square$ unmotivated $\square$ calm $\square$ nervous $\square$ relaxed $\square$ tired

3. If the teacher asks a question, I feel: (indicate a maximum of two options).

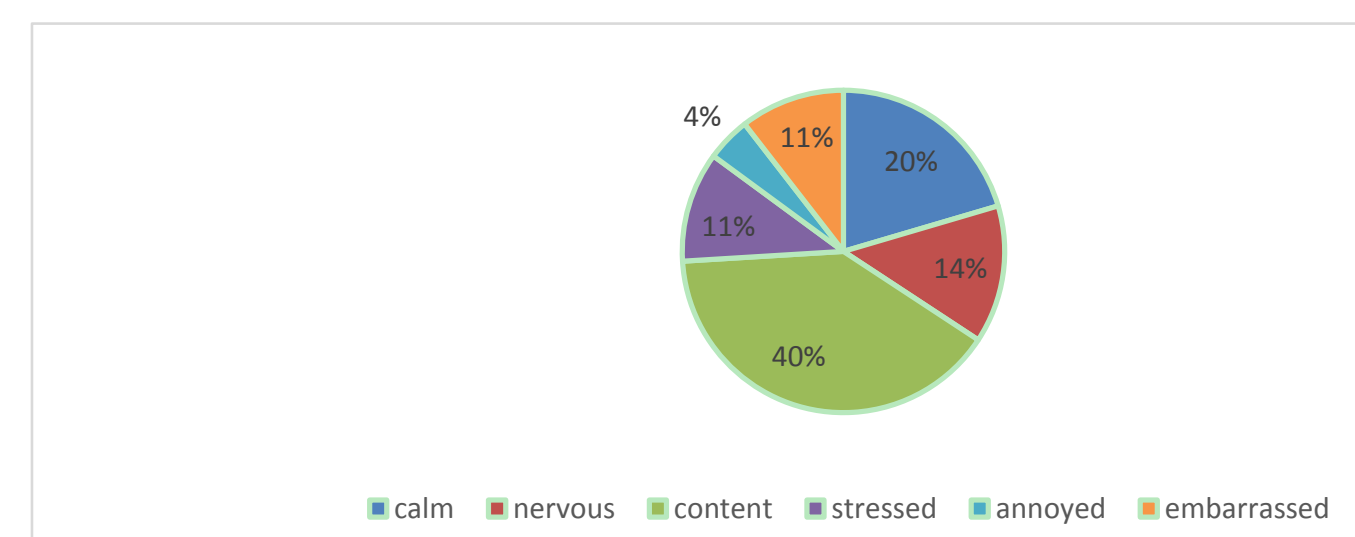




\section{If the teacher corrects me, I feel:}

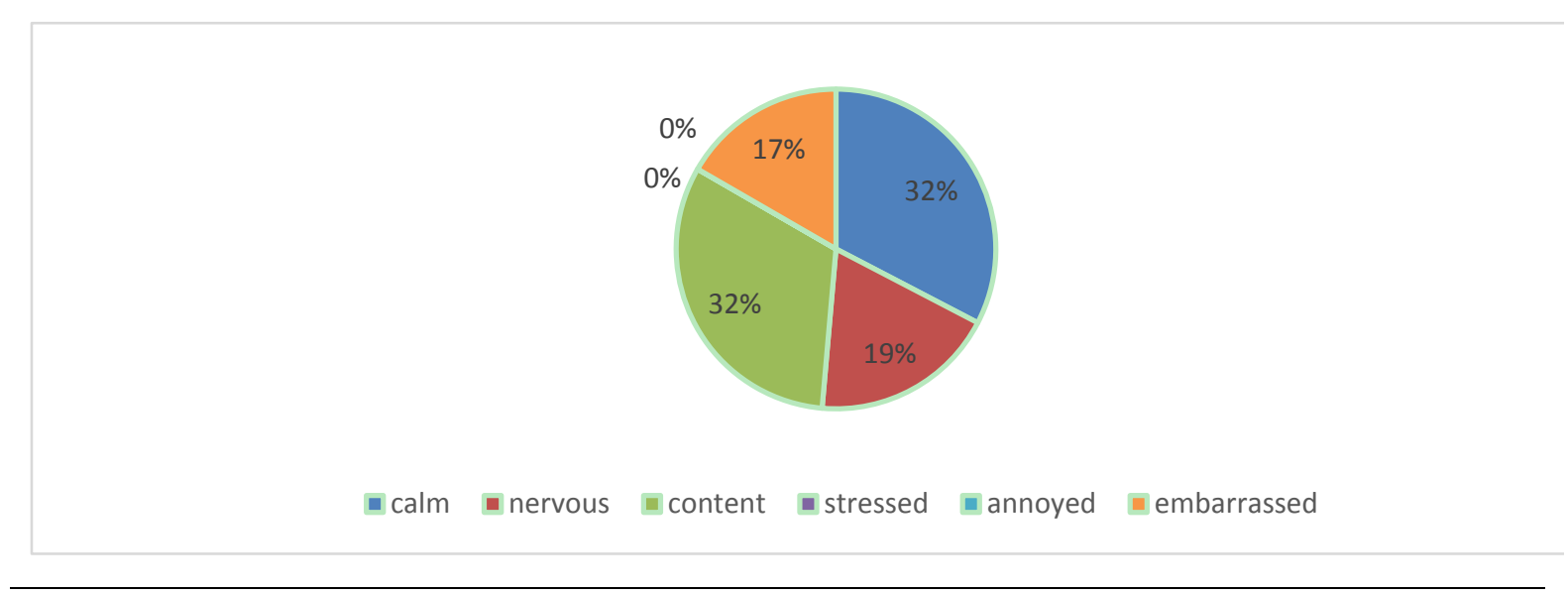

Figure 5. Analysis of the perception of IIC students in the classroom. Personal elaboration

The students' answers highlight the hedonistic and instrumental motivation for a cultural trip to Italy. This aspect is probably linked to the age group of students who, having more free time, can devote themselves to cultural activities.

Such a source of motivation allows the learner to enjoy a positive emotional state. In fact, $45 \%$ of the students say they feel comfortable during didactic situations in the classroom. However, the data obtained also shows some emotional and psychological implications as $11 \%$ of the students say they feel tired during the performance of didactic activities, while $15 \%$ confirm a nervous emotional state. This realisation made it necessary to conduct an operational verification of the classroom in order to detect whether the students' feelings correlate with physiological factors of fatigue or with the teaching model chosen by the teacher. For this reason, observation in the classroom has proved to be a valuable tool for identifying problems in learning courses. In this context, it has been observed that the origin of the students' stress may require a deeper level of explanation that calls into question the students' emotional and cognitive processes. It has been found that two of the most anxiety-provoking teaching situations are linked to the formulation of the direct question (100\% of the cases examined) and the treatment of error. In the first case, after a language presentation of the input, the teacher asks the student to answer a question in Italian without an effective assessment of the student's understanding. In the second case, the teacher describes an error while remaining at a surface level analysis of the form. The correction method is conducted through interrupting the speaker, transcribing the form on the board, explaining and then asking the student to rephrase their original wording in order to confirm that he or she understood the grammatical explanation. Such a modality does not take place within a communicative framework, is not useful for emphasizing notice, and generates stress and embarrassment for students. These factors obstruct linguistic acquisition and reveal a methodological reality that refers to the traditional learning processes in Japan. In line with the students' responses and observation in the classroom, the IIC Italian teacher has a spatial, semantic, verbal and quantitative dominance. The 'teacher talk' occupies almost all the lesson while the students remain poorly exposed to the use of the language and their intervention is 


\section{Macrothink}

International Journal of Linguistics

ISSN 1948-5425 2020, Vol. 12, No. 2

limited to two instances. The first is the reading and understanding of the text, where the learners refer to an electronic translator. The second instance is the execution of a grammatical clarification or a performed task. This linguistic behaviour on the teachers' part produces a gap between the lack of a communicative situation activated in the classroom and the communicative objective of the courses.

The outlined reference context is reflected in the second section of the questions aimed at detecting the strategies and teaching materials selected by the teacher to use in the classroom.

5. In class you use: (Indicate one or more options).

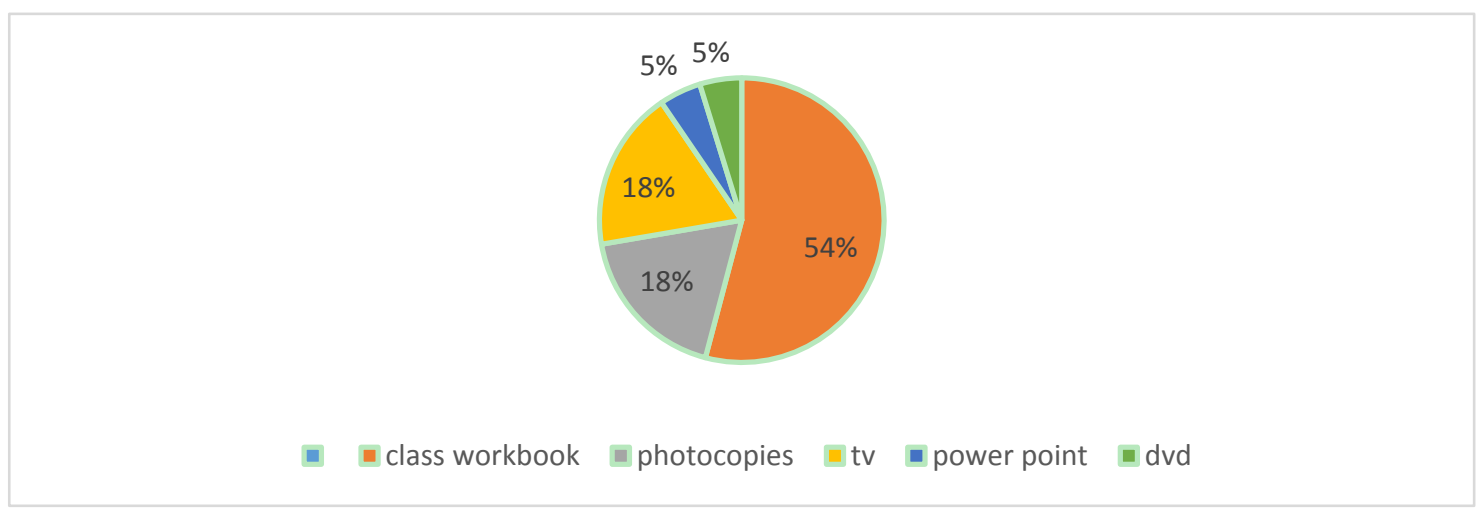

6. What activities do you do in the classroom? (Indicate one or more options).

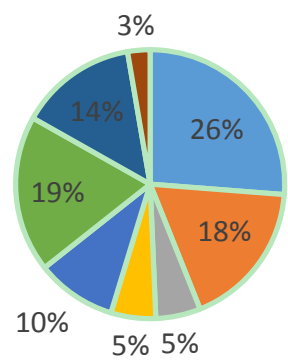

axercises

$\square$ readings of the text $\square$ translations

dictation

multiple choice

- listenings

- dialogues

- summary

7. In class, the Italian teacher: (Indicate a maximum of two options). 


\section{In class you:}

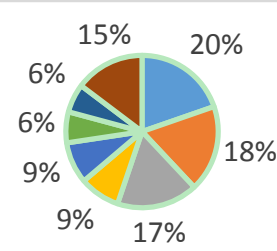

a speak Italian for a long time do many exercises

do many listenings

write a lot in Italian

- speak italian for a short time $\mathbf{d}$ do few exercises

- do few plays

- do not write a lot in Italian

\section{In class you study a lot of:}

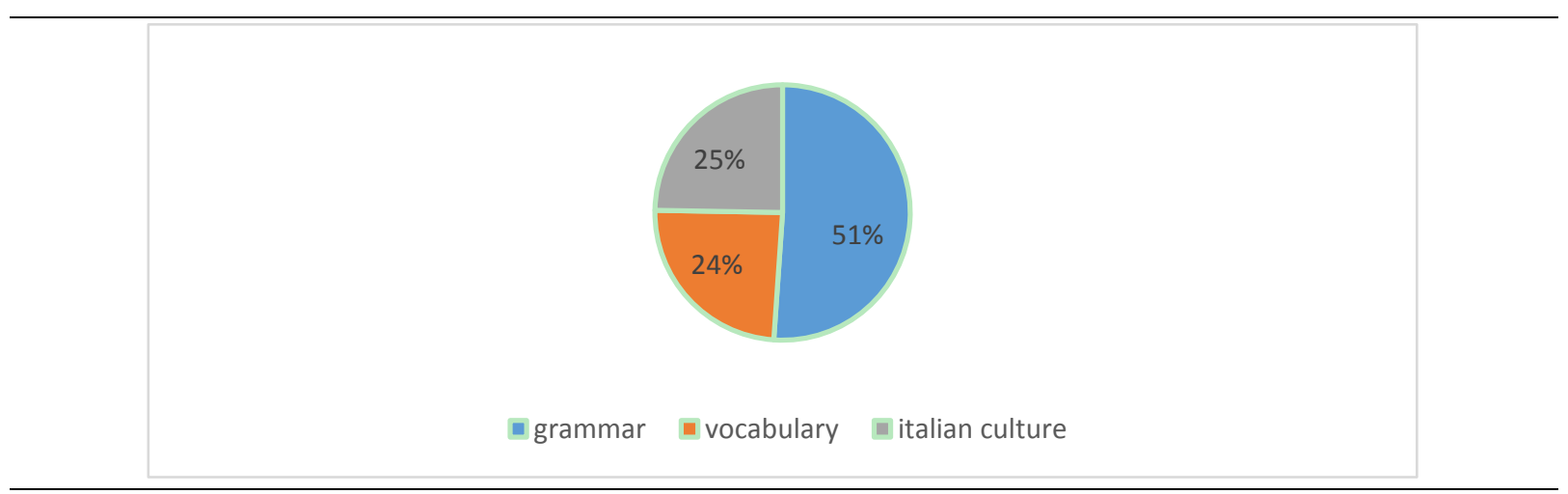

\section{In class you work:}

घalone $\square$ with a classmate $\square$ with a group of classmates $\quad$ with the entire class

The didactic frame that emerges from both the students' responses and from the observation in the classroom is that the advancement of communicative competence has different evaluation parameters with respect to fluency or other criteria that consider the complexity of the language. The language teaching integrates the grammatical approach, the translational approach and structural behaviours to sanction and correct the accuracy of the students. In fact, the students perceive being exposed to the language when they are called to do collaborative work with colleagues or to do tasks in which their working memory prevails in defining the level of correctness in class. The picture that emerges in this case is that the learner is called upon in the classroom to make interventions limited by frequency, duration and complexity and then to close the lesson, the learner executes individual tasks which are 
focused on the standard of learning. From a methodological point of view, the teacher provides the correct version of standard Italian through printed and multimedia texts from the course's user manual. This is done without activities that expose the learner to changes in the Italian new standard language or implementation of exploratory research paths of the socio-cultural aspects of Italian.

The formal correctness of these courses is expected to satisfy students, facilitating their Italian learning. In reality, when the third section of questions (Table 8) asked the learners to evaluate the effectiveness and adequacy of the teacher's method with respect to their objectives, the learners expressed awareness in having difficulties with the language level of the course (33\%). Despite this obstacle, the reputation towards the teacher is never questioned, in line with the cultural traits that distinguish the relationship between the teacher and the learner in Japan.

Table 8. Perception of the IIC students regarding the effectiveness of the teaching method. Personal elaboration

\begin{tabular}{|c|c|c|c|c|c|c|}
\hline \multirow{2}{*}{\multicolumn{3}{|c|}{$\begin{array}{lc}\begin{array}{l}\text { Do you agree or disagree? } \\
\text { Total responses: } 135\end{array} & \begin{array}{c}\text { Strongly } \\
\text { agree }\end{array} \\
\text { JUDGE BASED ON YOUR EXPERIENCE }\end{array}$}} & \multicolumn{3}{|c|}{ agree } & \multirow[t]{2}{*}{$\begin{array}{l}\text { Do not } \\
\text { agree }\end{array}$} \\
\hline & & & & & & \\
\hline \multicolumn{2}{|c|}{$\begin{array}{l}\text { I have positive feelings with } 105 \\
\text { the teacher }\end{array}$} & $77,7 \%$ & 30 & 22,3 & & \\
\hline $\begin{array}{l}\text { The teacher's method is } \\
\text { effective for learning Italian }\end{array}$ & & $62,2 \%$ & 33 & $24,4 \%$ & 18 & $13,3 \%$ \\
\hline $\begin{array}{l}\text { The teacher motivates me to } \\
\text { study more }\end{array}$ & & 67,4 & 33 & $24,4 \%$ & 11 & $8,1 \%$ \\
\hline $\begin{array}{l}\text { When the teacher speaks and } \\
\text { explains, I } \begin{array}{l}\text { understand } \\
\text { everything }\end{array}\end{array}$ & & $28,1 \%$ & 60 & $44,4 \%$ & 37 & $27,4 \%$ \\
\hline $\begin{array}{l}\text { When the course finishes, I will } \\
\text { be able to speak in Italian }\end{array}$ & & $21,4 \%$ & 61 & 45,1 & 45 & 33,3 \\
\hline
\end{tabular}

\section{Conclusion}

The research had the merit of highlighting the inconsistency between the teaching objectives and the way they are carried out in class. The results are transmission courses where the psycho-cognitive processes of the learner are not called into question. In fact, the learner's tasks are limited to the classroom and a mechanical action to carry out the task. Recast or reformulation strategies are rarely used for the purpose of reflecting on the functioning mechanisms of the language and therefore do not guide the students to make metalinguistic considerations regarding their own mistakes. In addition, the teacher's correction in a top-down manner focuses on the functioning of the rule, which diverts the attention from the communicative act for which the grammar is used. In this scenario, learning is a form of individualization and isolation where there is no formal recognition of the competence learned. Namely, there is no evaluation system that measures the effectiveness of the teacher's method and the level of motivation the student has for their course. 


\section{Mll Macrothink}

International Journal of Linguistics

ISSN 1948-5425

2020, Vol. 12, No. 2

Finally, the holistic approach of research proved useful in demonstrating the value and the impacts attributed to the investigation which allowed the identification of the problems as well as their relative solutions. (Mills, 2014). In view of what happens in the classroom, the dissemination of the research data should help teachers avoid incurring static and rigid interpretations of their teaching and assign the language a social role of interaction between people. According to Miller (2005) and McLeod (2015), by focusing on the problem and the motivations that produce it, teachers should re-evaluate the teaching situation and invest, first and foremost, in their own training. In this regard, the research has managed to identify a training requirement linked to the methodological aspect and to create a professional development and growth plan that is currently in the implementation phase.

Therefore, the outcome of the research is linked to the renewal strategy of the promotion of Italian by the IIC in Osaka. The IIC has decided to invest on an exploratory plan aimed at enhancing the Italian learning offer in Japanese society, starting with new ways to learn the language. In this renewal, the teachers and students represent the agents of the possible change while the didactic organization makes use of operational tools (curriculum, syllabus and ad hoc Italian language manuals) to demonstrate that the teaching is no longer just a mere transposition of concepts where it is sufficient to slow down proposing content without requiring efforts from learners. On the contrary, teachers consider internal characteristics of the class and become aware of methodological and technical strategies that provide a more authentic and lively use of the language. This can be done without compromising the order and the sequence of the acquisition structures foreseen by the syllabus. Moreover, it will benefit older learns learners in improving sociolinguistic adequacy and the pragmatic efficacy of their language at an oral and textual level. Finally, it becomes crucial for teachers to be able to take part in the training and glottodidactic updating which, in blended mode, was proposed in accordance with the direction of the IIC in order to be able to connect and reflect on the experience of the class. This can be done with new glottodidactic tools that allow widening the field of experimentation in teaching and being able to choose which strategies are best in class for students to acquire the language.

\section{References}

Al Wossabi, S. (2019). Integrated Curriculum for a Saudi University EAP Class. Journal of Language Teaching and Research, 10(2), 344-352. https://doi.org/10.17507/jltr.1002.17

Balboni, P. E. (2007). Operational models for Language Education. Perugia: Guerra.

Balgoa, N. G. (2019). Filipino English Teachers in Japan: "Nonnativeness" and the Teaching and Learning of English. Journal of Language Teaching and Research, 10(2), 256-263. https://doi.org/10.17507/j1tr.1002.06

Blake, M. K. (2007). Formality and Friendship: Some Reflections on the University Research Ethics Review Process. ACME- an International E-Journal for Critical Geographies, 6(3), 172-181. 


\section{Macrothink}

International Journal of Linguistics

ISSN 1948-5425

2020, Vol. 12, No. 2

Bolagari, M. S., \& Hajimaghsoodi, A. (2017). Action Research as a Bottom-up Approach to Foster Teacher Involvement in Language Curriculum Change. Journal of Language Teaching and Research, 8(2), 362-369. https://doi.org/10.17507/jltr.0802.20

Burns, A. (2011). Action research in the field of second language teaching and learning. In E. Hinkel (Ed.), Handbook of research in second language teaching and learning (pp. 237-253). New York: Routledge.

Carr, W., \& Kemmis, S. (1994). Becoming Critical. Lewes: Falmer Press.

Convery, A., \& Townsend, A. (2018). Action Research Update: Why Do Articles Get Rejected from EARJ?. Educational Action Research, 26(4), 1-10. https://doi.org/10.1080/09650792.2018.1518746

Creswell, J. W. (2003). Research design: Qualitative, quantitative, and mixed methods approaches. Thousand Oaks, CA: Sage.

Diadori, P., Peruzzi, P., \& Zamborlin, C. (2017). Insegnare italiano L2 a giapponesi. Roma: Edilingua.

Dörnyei, Z. (2014). Researching complex dynamic system: Retrodictive qualitative modelling in the language classroom. Language Teaching, 47(1), 80-91.

Fujita-Round, S., \& Maher, J. C. (2008). Language Education Policy in Japan. In N. H. Hornberger (Ed.), Encyclopedia of Language and Education. Springer, Boston, MA.

Glenn, M. (2011). Developing holistic practice through reflection, action and theorising. Educational Action Research, 489-502. https://doi.org/10.1080/09650792.2011.625694

Gottlieb, N. (2008). Japan: Language Policy and Planning in Transition. Language Planning, 9, 1-68.

Grabe, W., \& Stoller, F. L. (2013). Teaching and Research Reading. NY: Routledge.

Hashimoto, K. (2009). Cultivating "Japanese who can use English": Problems and contradictions in government policy. Asian Studies Review, 33(1), 21-42. https://doi.org/10.1080/10357820802716166

Hino, N. (1988). Yakudoku: Japan's Dominant Tradition in Foreign Language Learning. Jalt Jurnal, 10(1-2), 45-55.

Horiguchi, S., Imoto, Y., \& Poole, G. S. (2015). Foreign Language Education in Japan. Rotterdam: Sense Publishers.

Kariya, T. (2012). Education reform and social class in Japan: The emerging incentive divide. London: Routledge.

Karnieli, M. (1998). Holistic educational intervention as an action model for the professional development of teacher educators. Educational Action Research, 6(3), 395-412. https://doi.org/10.1080/09650799800200066 
Kemmis, S., McTaggart, R., \& Nixon, R. (2014). The Action Research Planner: Doing Critical Participatory Action Research. Singapore: Springer.

Kikuchi, K., \& Browne, C. (2009). English educational policy for high schools in Japan: Ideals vs. reality. RELC Journal, 40(2), 172-191. https://doi.org/10.1177\%2F0033688209105865

Kubota, R. (2016). Neoliberal paradoxes of language learning: Xenophobia and international communication. Journal of Multilingual and Multicultural Development, 37(5), 467-480. https://doi.org/10.1080/01434632.2015.1071825

Kunishig, T., Takahashi, A., \& Harada, N. (2011). An analysis of the students' motivation for studying English at Tokuyama College of Technonology. Research Reports of the Council of College English Teachers, 30, 15-24.

Lombardi Vallauri, E. (2018). Difficoltà dei giapponesi con la pronuncia di parole italiane ed inglesi: i risultati di un esperimento. In A. Manco (Ed.), Le lingue extra-europee e l'italiano: aspetti didattico-acquisizionali e sociolinguistici. Atti del LI Congresso Internazionale di Studi della Società di Linguistica Italiana (pp. 249-273). Roma: SLI.

Mamiko, N., \& O’Regan, J. P. (2019). L1 marginalisation in Japan: monolingual instrumentalism and the discursive shift against yakudoku in the Japanese government's Course of Study. Current Issues in Language Planning. https://doi.org/10.1080/14664208.2019.1647998

Mckenzie, R. B. (2008). The complex and rapidly changing sociolinguistic position of the English language in Japan: a summary of English language contact and use. Japan Forum, 20(2), 267-286. https://doi.org/10.1080/09555800802047525

McLeod, N. (2015). Reflecting on Reflection: Improving Teacher's Readiness to Facilitate Participatory Learning with Young Children. Professional Development in Education, 41(2), 254-272. https://doi.org/10.1080/19415257.2013.805306

McRostie, J. (2017). As Japan's JET Programme hits its 30s, the jury's still out. Japan Times. Retrieved January 10, 2018, from https://www.japantimes.co.jp/community/2017/05/03/issues/japans-jet-programme-hits-30s-j urys-still/\#.W8KU2i2B2JI

Miller, J. P. (2005). Conclusion: Seeking Wholeness. In J. P. Miller (Ed.), Holistic learning and spirituality in education. Breaking new ground (pp. 233-236). Albany: State University of New York Press.

Mills, G. E. (2014). Action Research: A Guide for the Teacher Researcher. New York: Pearson.

Ministry of Education Culture Sports Science and Technology. (2017). Chūgakkō gakushū shidō yōryō, Course of study for lower secondary schools. Retrieved December 29, 2019, from http://www.mext.go.jp/a_menu/shotou/new-cs/youryou/index.htm 


\section{Macrothink}

International Journal of Linguistics

ISSN 1948-5425

2020, Vol. 12, No. 2

Ministry of Education Culture Sports Science and Technology. (2018). Kōtōgakkō gakushū shidō yōryō, Course of study for upper secondary schools. Retrieved January 14, 2020, from http://www.mext.go.jp/a_menu/shotou/new-cs/1384661.htm

Nassaji, H. (2019). Good research questions. Language Teaching Research, 23(3), 283-286. https://doi.org/10.1177/1362168819845322

Nugent, K. L. (2019). Exploring the teaching of culture in the foreign language classroom within the context of collaborative professional development: a critical participatory action research study. Educational Action Research. https://doi.org/10.1080/09650792.2019.157714

Pennycook, A. (2017). The cultural politics of English as an international language. New York: Routledge.

Pérez-Peittx, M., Civera Lopez, I., \& Sangrà, J. (2019). Awareness of Plurilingual Competence in Teacher Education. In P. Kalaja, \& S. Melo-Pferifer (Eds.), Visualing Multilingual Lives (pp. 232-253). Bristol: Multilingual Matters.

Rose, H., \& McKinley, J. (2018). Japan's English-medium instruction initiatives and the globalization of higher education. Higher Education, 75(1), 111-129. https://doi.org/10.1007/s10734-017-0125-1

Sampson, R. (2016). Complexity in Classroom Foreign Language Learning Motivation, A Practitione Perspective from Japan. Bristol: Multilingual.

Sergeant, P. (2011). Introduction: English in Japan in the era of globalization. In P. Sergeant (Ed.), English in Japan in the Era of Globalization (pp. 187-204). Basingstoke: Palgrave Mcmillan.

Thompson, G., \& Yanagita, M. (2017). Backward yakudoku: An attempt to implement CLT at a Japanese high school. Innovation in Language Learning and Teaching, 11(2), 177-187. https://doi.org/10.1080/17501229.2015.1088856

Turnbull, B. (2017). Learner Perspectives on National Identity and EFL Education in Japan: Report of a Questionnaire Study. The Journal of Asia TEFL, 14(2), 211-227.

Ushioda, E. (2015). Context and complex dynamic system theory. In Z. Dornyei, P. D. MacIntyre, \& Henry, A. (Eds.), Motivation Dynamics in Language Learning (pp. 47-54). Bristol: Multilingual Matters.

Zamborlin, C. (2003). Didattica dell'italiano in Giappone. Un'avventura contrastiva sul piano linguistico e pedagogico. Rivista ITALS. Didattica e linguistica dell'italiano come lingua straniera, 1(2), 109-125. 


\section{Notes}

Note 1. The conceptual contributions of this article are the result of collaboration by both authors. Specifically, sections 1-2-5 written by Graziano Serragiotto and sections 3-4 are attributed to Giuseppe Maugeri. Translation by Lama Alhelou.

Note 2. http://www.mext.go.jp/en/

\section{Copyrights}

Copyright for this article is retained by the author(s), with first publication rights granted to the journal.

This is an open-access article distributed under the terms and conditions of the Creative Commons Attribution license (http://creativecommons.org/licenses/by/4.0/) 